NBSIR 83-2785

\title{
Density Effect for the lonization Loss of Charged Particles in Various Substances
}

Department of Physics

Brookhaven National Laboratory

Upton, New York 11973

U.S. DEPARTMENT OF COMMERCE National Bureau of Standards Center for Radiation Research

Washington, DC 20234

November 1983

Prepared icr:

U.S. DEPARTMENT OF COPNMERCE

National Bureau of Standards

Cffice of Standard Reference Data

Washington, DC 20234

U.S. Department of Energy

Washington, DC 20545

Office of Naval Research

Ariington, Virginia 22217 

DENSITY EFFECT FOR THE IONIZATION

LOSS OF CHARGED PARTICLES IN

\section{VARIOUS SUBSTANCES}

R. M. Sternheimer

Department of Physics

Brookhaven National Laboratory

Upton, New York 11973

M. J. Berger and S. M. Seltzer

U.S. DEPARTMENT OF COMMERCE

National Bureau of Standards

Center for Radiation Research

Washington, DC 20234

November 1983

Prepared for:

U.S. DEPARTMENT OF COMMERCE

National Bureau of Standards

Office of Standard Reference Data

Washington, DC 20234

U.S. Department of Energy

Washington, DC 20545

Office of Naval Research

Arlington, Virginia 22217

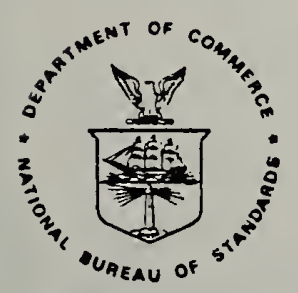

U.S. DEPARTMENT OF COMMERCE, Malcolm Baldrige, Secretary NATIONAL BUREAU OF STANDARDS, Ernest Ambler. Director 



\title{
DENSITY EFFECT FOR THE IONIZATION LOSS \\ OF CHARGED PARTICLES IN VARIOUS SUBSTANCES ${ }^{*}$
}

\author{
R. M. Sternheimer \\ Department of Physics \\ Brookhaven National Laboratory \\ Upton, New York 11973 \\ M. J. Berger and S. M. Seltzer \\ Center for Radiation Research \\ National Bureau of Standards \\ Washington, D.C. 20234
}

\section{ABSTRACT}

The density-effect correction $\delta(\beta)$ for the ionization energy loss of charged particles has been evaluated for a total of 278 substances including 98 cases of elements of the Periodic Table (12 gases and 86 condensed materials, including liquid hydrogen and graphite of three different densities) and including also 180 chemical compounds and substances of biological interest (13 gases and 167 liquid or solid substances). In the calculations, up-to-date values of the mean excitation potential I and of the atomic absorption edges $h v_{i}$ were employed as input data for the general equations for o( $\beta$ ) previously derived by Sternheimer.

${ }^{*} A$ version of this report with a shortened text but the same tables will appear in Atomic Data and Nuclear Data Tables. 


\section{Introduction}

The density-effect correction $\delta$ for the ionization loss of charged particles 1-12 has been evaluated previously for a large number of substances. ${ }^{5-12}$ The last previous extensive effort in this direction was made in the paper of Sternheimer, Seltzer, and Berger 12 in which the density effect was evaluated for a total of 72 substances (34 metallic elements, 26 compounds, 11 gases and liquid hydrogen). In Ref. 12, the basic equations of Sternheimer (Refs. 3 and 5) were used in order to evaluate the density effect, employing up-to-date values of the mean excitation potential ${ }^{13-14} \mathrm{I}$, and of the atomic absorption edges ${ }^{15} \mathrm{~h} v_{i}$.

In the present work, the results of Ref. 12 have been extended to a total of 278 substances including 98 cases of elements of the Periodic Table (12 gases and 86 condensed materials including liquid hydrogen and graphite of three different densities) and including also 180 chemical compounds and substances of biological interest (13 gases and 167 liquid or solid compounds). The essential advance of the present calculations over those previously carried out in Refs. 5-12 consists in the development and implementation of a computer algorithm which carries out in a single operation the numerical evaluation of the density effect and the fitting of the numerical results by an approximation formula.

\section{Numerical Evaluation of the Density Effect}

The calculations of $\delta(\beta)$ are based on the following equations derived by Sternheimer ${ }^{3,5}$ in 1945 and 1952:

$$
\delta(\beta)=\sum_{i=1}^{n} f_{i} \text { ln }\left[\left(\ell_{i}^{2}+\ell^{2}\right) / \ell_{i}^{2}\right]-\ell^{2}\left(1-\beta^{2}\right) \text {, }
$$


where $B=v / c$ is the particle velocity divided by the velocity of light, and $\ell$ is the solution of the equation:

$$
\frac{1}{\beta^{2}}-1=\sum_{i=1}^{n} \frac{f_{i}}{v_{i}^{2}+\ell^{2}} \text {. }
$$

In Eq. (2), $\bar{v}_{i}$ is defined by:

$$
\bar{v}_{i}=v_{i} \rho / v_{p}
$$

where $h v_{i}$ is the absorption edge for the $i^{\text {th }}$ oscillator of the dispersion model. The quantity $h \nu_{p}$ is the plasma energy of the electrons of the substance considered as free electrons, and is given by 16

$$
h \nu_{p}=28.816\left(\rho_{0} Z / A\right)^{1 / 2} \mathrm{eV}
$$

where $\rho_{0}$ is the density of the medium (in $\mathrm{g} / \mathrm{cm}^{3}$ ), $Z$ is the atomic number and $A$ is the atomic weight. In the case of a compound or molecular gas, Z/A is to be repiaced by the ratio of the total number of electrons to the effective molecular weight or the sum of atomic weights of the constituent atoms: $\Sigma Z_{i} / \Sigma A_{i}$. As in Ref. 12, a separate dispersion oscillator is used for each subshell of the atom considered, e.g., $K, L_{I}, L_{I I}$, and $L_{I I I}$ for neon. The quantity $\circ$ in Eq. (3) is the adjustment factor which was introduced by Sternheimer 5 in 1952 and which is designed to give agreement of the oscillator energies $h v_{i} \rho$ (or rather $h v_{p} l_{i}$ ) with the observed mean excitation potential $I$. Specifically, in Eq. (1), the constants $\ell_{i}$ are defined by:

$$
\ell_{i} \equiv\left(\bar{v}_{i}^{2}+\frac{2}{3} f_{i}\right)^{1 / 2} \text { for } \quad \bar{v}_{i}>0
$$




$$
\ell_{n}=f_{n}^{1 / 2} \text { for } \quad \bar{v}_{n}=0 \quad \text { (conduction electrons in a metal). }
$$

In Eq. (5), the factor $2 / 3$ takes into account the Lorentz-Lorenz correction [see Ref. 5, Eqs. (48)-(52)] in the expression for the polarizability $\alpha(\nu)$; note that this factor does not enter for the case of conduction electrons for which $\ell_{n}=f_{n}^{1 / 2}$, as given above.

The mean excitation potential I of the medium is given by

$$
\ln I=\sum_{i} f_{i} \ln \left(h \nu_{p} \ell_{i}\right)
$$

By making use of Eq. (3) for $\bar{v}_{j}$, we obtain the following expression, which is used to determine the value of the Sternheimer adjustment factor $\rho$ :

$$
\ln I=\sum_{i=1}^{n-1} f_{i} \ln \left[\left(h \nu_{i} \rho\right)^{2}+\frac{2}{3} f_{i}\left(h \nu_{p}\right)^{2}\right]^{1 / 2}+f_{n} \ln \left(h \nu_{p} f_{n}^{1 / 2}\right) \text {. }
$$

For a conductor, $f_{n}$ is taken as $n_{c} / Z$, where $n_{c}$ is the effective number of conduction electrons per atom of the substance. Note that for a compound (insulator) or for a gas, $n_{c}=0$, the sum in Eq. (8) extends from $i=1$ to $n$, and the last term on the right-hand side of Eq. (8) is not present. The values of $\rho$ thus determined from the experimental values of $I$ and $h v_{j}$ lie generally in the range $1.5-2.5$. Physically the meaning of $\rho$ is that it takes into account the fact that for the excitations of an inner shell with absorption edge $h v_{i}$, the contribution of the excitation (ionization) to continuum states involves energies which are larger than $h \nu_{j}$. A very approximate estimate of $\rho$ was made in Ref. 12 [Eq. (11)], with the result that $\rho$ is of the order of $\mathrm{e}^{1 / 2}=1.649$. 
In Eqs. (1), (2), and (5)-(8), $f_{i}$ is the oscillator strength for the $i^{\text {th }}$ oscillator, which was taken as $n_{j} / Z$ for the inner (non-conduction) electrons; here $n_{i}$ is the number of electrons for the subshell considered, e.g., $n_{i}=4$ for the $L_{\text {III }}$ subshell. In the case of a metal, $n_{c}$ was taken to be the lowest chemical valence of the element considered. " The values of the absorption edges $h v_{i}$ for the various subshells of all elements were obtained from the compilation of Carlson. ${ }^{15}$ The values of I were obtained from two recent papers of Berger and Seltzer. 13,14

In Fig. 1, we have plotted the values of the Sternheimer adjustment factor $\rho$ as a function of $Z$. The solid curve has been drawn through the $\rho$ values for metals as obtained by means of $\mathrm{Eq}$. (8). The $\rho$ values for the 12 gases are shown separately as crosses. It can be seen that except for the four gases $\mathrm{O}_{2}, \mathrm{~N}_{2}, \mathrm{~F}$, and $\mathrm{Ne}$, the crosses lie very close to the curve determined by the $\rho$ values for condensed substances. The most striking feature of the curve of Fig. 1 is the existence of successive maxima and minima as a function of $z$. The maxima and minima reflect the existence of similar features in the curve of $I / Z$ vs. $Z$, as presented in Fig. 1 of Ref. 12, but in the present case, i.e., for $o$, these fluctuations are much more pronounced. They can be related to the electronic shell structure of the atoms considered.

\footnotetext{
* An alternative prescription would be to use as the effective number of conduction electrons the number of electrons participating in plasma excitations in metals. The latter number can be deduced from optical data and from measured electron energy-loss spectra. Effective numbers of plasina electrons have been deduced from the experimental literature by Raether 17 for 27 metais and by Isaacson 18 for 47 metals; see also Mann and Brandt, 19 and Ziegler, Biersack and Littmark. 20 We have made some numerical tests, and have found, for example, that the use of resuits of Raether or Isaacson would change the density-effect correction such that the electron stopping power in gold would differ by less than $0.3 \%$ and that in copper by less than $0.25 \%$, compared to the values obtained when the number of conduction electrons is deduced from the lowest valence state.
} 
Thus the maxima at $Z=11, Z=30, Z=47$, and $Z=70$, correspond approximately to the filling of the $2 p^{6}, 3 d^{10}, 4 d^{10}$, and $4 f^{14}$ shells, respectively. In addition, the pronounced shoulder in the neighborhood of $Z=80 \mathrm{can}$ be correlated with the completion of the $5 d^{10}$ shell in this region of the Periodic Table.

On the other hand, the minima of $\rho$ at $z \cong 20, Z=39, Z=57$, and $Z=89$ correspond approximately to the filling of the $\mathrm{ns}^{2}$ shell in the alkaline earths $\mathrm{Ca}(Z=20), \operatorname{Sr}(Z=38), \mathrm{Ba}(Z=56)$, and $\mathrm{Ra}(Z=88)$, respectively. We would like to note that these alkaline earths correspond to the closing of the successive supershells ${ }^{21}$ of the Periodic Table, where a supershell is defined as the set of all shells ne with the same value of the quantum number $k=n+\ell$. Thus both the curves $I / Z$ vs. $Z$ and $\rho \underline{v s} . Z$ give additional support to the $k$ ordering of atomic structure. ${ }^{22}$

\section{Fittina Formula}

Using the procedures described above, numerical values of $\delta(\beta)$ were calculated for each material at many points on a logarithmically spaced energy grid. The energy variable used was $T / m_{0} c^{2}$, where $T$ is the kinetic energy and $m_{0} c^{2}$ is the particle rest energy. The grid values were chosen to be $T_{(i)} / m_{0} c^{2}=100,000,80,000,60,000,50,000,40,000,30,000,20,000,15,000$, 10,000 , and so on, down to $T_{(i)} / \mathrm{m}_{0} \mathrm{c}^{2}=0.01$. The numerical values of $\delta$ were fitted to the formula proposed by Sternheimer 5 in 1952, namely:

$$
\begin{array}{ll}
\delta(x)=4.6052 x+a\left(x_{1}-x\right)^{m}+c, & \left(x_{0}<x<x_{1}\right) \\
\delta(x)=4.6052 x+c, & \left(x>x_{1}\right)
\end{array}
$$


where $X \equiv \log _{10}\left(p / m_{0} c\right)=\log _{10}(B \gamma)=1 / 2 \log _{10}\left[\left(T / m_{0} c^{2}\right)\left(T / m_{0} c^{2}+2\right)\right]$, with $p$ the momentum of the incident particle and $\gamma=\left(1-\beta^{2}\right)-1 / 2 . \quad x_{0}$ is the value of $X$ below which $\delta(X)$ is zero for the case of an insulator or gas, and the value of $x$ below which $\delta(X)$ for a metal (conductor) is sma11, i.e., $\delta(x)<0.14$. $x_{1}$ is the value of $x$ above which $\delta(X)$ has essentially attained its asymptotic value (to within 0.015). In Eqs. (9) and (10), a and m are adjustable parameters which will be determined below, and $C$ is given by:

$$
C=-2 \ln \left(I / h \nu_{p}\right)-1 \text {, }
$$

where $I$ is the mean excitation potential of the substance for use in the Bethe-Bloch stopping-power formula. 23,24 In the present paper, we will frequently use the notation $\bar{C}$ for $-C=|C|$.

\section{Determination of the Parameters in the Fitting Formula}

The experience of Sternheimer $5-10$ in fitting $\delta(\beta)$ indicates that $x_{1}$ of Eq. (9) can be taken as that value of $X$ for which the deviation of $\delta(X)$ from its asymptotic value [Eq. (10)] is of the order of 0.01 , and in particular does not exceed 0.015 .

For each grid value $X_{(i)}$, the computer program calculates the values of $\delta$ and $\delta_{a s}$, the asymptotic value defined by Ea. (10). We define $\delta_{1}$ as follows:

$$
\delta_{i} \equiv \delta-\delta_{a s}
$$

Furthermore we define $x_{a}$ as follows [see Ref. 10, Eq. (8)]:

$$
x_{a} \equiv \bar{c} / 4.6052
$$


Incidentally, the physical significance of the difference $\delta_{1}$ is clearly shown (for the case of neon gas at normal temperature and pressure) in Fig. 1 of Ref. 10.

\subsection{Non-Conductors}

We first consider the case of non-conducting materials for which $\delta(B)=0$ at low velocities $\beta<\beta_{0}$, where $\beta_{0}$ is the velocity for which $\ell^{2}=0$ according to Eq. (2). We then have $x_{0}=\log _{10}\left(\beta_{0} \gamma_{0}\right)$, where $\gamma_{0}=\left(1-\beta_{0}^{2}\right)^{-1 / 2}$. After $X_{0}$ has been thus determined it is necessary to determine $X_{1}$ in Eqs. (9) and (10). Now the numerical values of $\delta_{1}$, to be denoted by $\delta_{1}$, num [see Eq. (12)] are approximated by the monomial expression $a\left(X_{1}-X\right)^{m}$, as shown by Eq. (9). We will denote the fitted values of $a\left(x_{1}-x\right)^{m}$ at the mesh points by $\delta_{1}$, fit ${ }^{\text {. }}$

Thus we have

$$
\delta_{1, f i t}(x)=a\left(x_{1}-X\right)^{m}
$$

The values of $x_{1}$, a and $m$ must be so chosen as to minimize the maximum deviations:

$$
\Delta \delta_{1} \equiv \delta_{1, f i t}-\delta_{1, \text { num }}
$$

We have one condition relating $a, m, x_{0}$, and $x_{1}$, namely that $\delta\left(x_{0}\right)=0$. From Eq. (9) we obtain directly:

$$
4.6052 x_{0}+a\left(x_{1}-x_{0}\right)^{m}-\bar{c}=0 \text {, }
$$

where $\bar{C} \equiv-C$. Upon solving for a, and using Eq. (13), one finds that 


$$
a=\frac{4.6052\left(x_{a}-x_{0}\right)}{\left(x_{1}-x_{0}\right)^{m}} .
$$

The remaining task is to determine the best values of $x_{1}$ and $m$. For each insulator or gas, nine separate calculations were run with $x_{1}$ determined by the condition that $\delta_{1}\left(X_{1}\right)$ [see Eq. (12)] has the values $0.0015,0.002,0.003$, $0.004,0.005,0.006,0.008,0.010$, and 0.015 , respectively. This procedure directly limits the maximum inaccuracy introduced by neglecting the numerical value of $\delta_{1}=\delta-\delta_{\text {as }}$ for $x>x_{1}$. The resulting errors are certainly tolerable because when the stopping number is $\sim 20$, an error of 0.015 in $\delta(X)$ introduces a relative error of only $0.015 / 20=0.00075=0.075 \%$.

The equation for a and the above procedure for determining a reasonable range of values of $x_{1}$ leave only the exponent $m$ undetermined. In the previous fits in Refs. 5, 7-10, and 12, it was found that it is best to require an exact fit of Eq. (9) to the numerical value of $\delta_{1, \text { num }}$ at one additional point in the range $x_{0}<x<x_{1}$, preferably for an $x$ value near the value of $x_{a}$ defined by Eq. (13). This intermediate $X$ value for which the additional fit was made will be denoted by $x_{2}$. Trial values of $x_{2}$ were chosen to be the ten grid points $x_{(i)}$ immediately below, and the ten grid points $x_{(i)}$ immediately above $x_{a}$ defined by Eq. (13), subject to the condition that $x_{0}<x_{2}<x_{1}$. We can now solve for $m$ as follows. For a given value of $x_{2}$, we have:

$$
a\left(x_{1}-x_{2}\right)^{m}=\delta_{1}\left(x_{2}\right)
$$

In view of the definition of $\delta_{1}\left(x_{0}\right)$ and the requirement of an exact fit at $x=x_{0}$, we have also:

$$
a\left(x_{1}-x_{0}\right)^{m}=s_{1}\left(x_{0}\right) .
$$


Dividing Eq. (19) by Eq. (18),

$$
\frac{\delta_{1}\left(x_{0}\right)}{\delta_{1}\left(x_{2}\right)}=\left(\frac{x_{1}-x_{0}}{x_{1}-x_{2}}\right)^{m} \text {, }
$$

and therefore:

$$
m=\frac{\log _{10}\left[\delta_{1}\left(x_{0}\right) / \delta_{1}\left(x_{2}\right)\right]}{\log _{10}\left[\left(x_{1}-x_{0}\right) /\left(x_{1}-x_{2}\right)\right]} .
$$

With $m$ thus determined ${ }^{\star \star}$ and for the given values of $X_{1}$ and $X_{0}$, a can now be obtained from Eq. (17).

The following computer algorithm was used for selecting the parameters a and $\mathrm{m}$ :

1. For each trial combination $X_{1}$ and $X_{2}$, a and $m$ were calculated according to Eqs. (17) and (21).

2. These trial values of a and $m$ were used to evaluate $\delta_{1}$, fit according to Eq. (9) at each grid-point $X_{(i)}$ between $X_{0}$ and $X_{1}$, and the maximum difference $\Delta_{\max }=\left|\delta_{1, \text { fit }}-\delta_{1, \text { num }}\right|$ for the trial was noted.

\footnotetext{
** It shouid be noted that $\delta$ is a monotonically increasing function of $x$. This condition is satisfied only when the fitting parameter $m$ is smaller than a maximum value $m_{\max }$ which -- for insulators and gases -- is given byll $m_{\max }=\frac{x_{1}-x_{0}}{x_{a}-x_{0}}$. In 26 of the 278 cases considered, the fitting procedure resulted in a value of $m$ somewhat larger than $m_{\text {max }}$, with the result that (for compounds) the value of $\delta$ from Eq. (9) was slightly negative in a narrow energy region near threshold. These values of $m$ were nevertheless accepted because the resulting error was negligible, the absolute value of $\delta$ in this region being smaller than $\sim 0.02$.
} 
3. This procedure was repeated in 180 trials, i.e., using the 9 choices of $x_{1}$ and 20 choices of $x_{2}$ discussed earlier. The values of $x_{0}, x_{1}$, $a$ and $m$ finally selected were those from the trial giving the smallest value of $\Delta_{\max }$. Values of these parameters will be given in Tables I and II.

\subsection{Conductors}

We now proceed to a discussion of the density effect for metallic conductors. In this case, $\delta(\beta)$ does not vanish for arbitrarily small velocities, as already discussed by Sternheimer in Ref. 7 . The basic reason is that for substances with conduction electrons, Eq. (2) contains a term with $\bar{v}_{n}=0$, and this leads to the result that $\ell^{2}>0$ for any nonvanishing $\beta^{2}$. Therefore a suitable value of $x_{0}$ must be chosen for which $\delta\left(x_{0}\right)$ is small, but not zero. $X_{0}$ cannot be made too small algebraically (e.q., very negative), since this would spoil the overall fit to Eq. (9) at larger values of $X$. It has been our general experience in obtaining the fits published in Ref. 12 that $X_{0}$ must generally be chosen such that $\delta\left(X_{0}\right)$ is close to 0.1 in all cases (see Table I of Ref. 12). In view of this observation, and in order to widen the choice of parameters so as to obtain the smallest values of $\Delta_{\max }$, the computer program was run for each of the 180 aforementioned choices with an additional choice of five values of $x_{0}$, such that the calculated values of $\delta\left(X_{0}\right)$ were $0.06,0.08,0.10,0.12$, and 0.14 , respectively. Thus a total of $180 \times 5=900$ possible fits were run for each metallic substance, and again that fit was chosen which gives the smaliest value of $\Delta_{\max }$. 
For the case of metals, the equations for $a$ and $m_{\text {max }}$ are slightly changed because $\delta\left(x_{0}\right)$ is not zero. The appropriate equations have been derived in Ref. 11 and are as follows: We define $x_{a, \delta}$ by

$$
x_{a, \delta} \equiv \frac{\bar{c}+\delta\left(x_{0}\right)}{4.6052}
$$

In terms of $x_{a, \delta}$ the modified equations for $a$ and $m_{\max }$ are given by:

$$
\begin{gathered}
a=\frac{4.6052\left(x_{a, \delta}-x_{0}\right)}{\left(x_{1}-x_{0}\right)^{m}}, \\
m_{\max }=\frac{x_{1}-x_{0}}{x_{a, \delta}-x_{0}} .
\end{gathered}
$$

Obviously, for insulators $\left[\delta\left(x_{0}\right)=0\right], x_{a}, \delta$ reduces to $x_{a}$ as defined above [Eq. (13)].

For metals we have found that the density effect $\delta$ for $X$ belo's $X_{0}$ can be approximated satisfactorily by the formula

$$
\delta(x)=\delta\left(x_{0}\right) \times 10^{2\left(x-x_{0}\right)}, \quad x<x_{0} .
$$

The error in $\delta$ incurred by the use of Eq. (25) is always smaller than the uncertainty $\Delta_{\max }$ for the fit above $x_{0}$.

Before we proceed to a detailed explanation of Tables I and II, we note that in some cases, for the 72 substances considered by us in Ref. 12, although the same values of the mean excitation potential I were used, the new values of $a$ and $m$ are nevertheless appreciably different. For example, for 
borosilicate glass (Pyrex) we have $a_{1}=0.2988$ and $m_{1}=2.805$ in the fit of Ref. 12 (with $x_{0}=0.1479, x_{1}=2.5$ ) and we have $a_{2}=0.08270$ and $m_{2}=3.5224$ (with $x_{0}=0.1479, X_{1}=2.9933$ ) in the present fit. For gold, we found $a_{1}=0.1533$ and $m_{1}=2.881$ (with $x_{0}=0.0966, \delta\left(x_{0}\right)=0.0912 ; x_{1}=3.5$ ) in Ref. 12, and $\mathrm{a}_{2}=0.09756$ and $\mathrm{m}_{2}=3.1101$ (with $\mathrm{X}_{0}=0.2021, \delta\left(\mathrm{X}_{0}\right)=0.14$; $\left.x_{1}=3.6979\right)$ in the present work. Even though the parameters $a$ and $m$ are individually quite sensitive to the choices of $X_{0}, X_{1}, X_{2}, \delta_{1}\left(X_{1}\right)$ (and $\delta_{0}\left(x_{0}\right)$ in the case of metals), the variations of a and $m$ are correlated so that the fitted values $\delta_{f i t}$ are quite similar.

We note that the compositions for the various substances, in particular for the organic compounds and the biological substances, are not listed in Table II. For those compositions, the reader is referred to the recent paper of Seltzer and Berger. ${ }^{13}$

\section{Example of the Use of Tables I and II}

The density-effect correction $\delta$ is to be used in the Bethe stopping-power formula

$$
-\frac{1}{\rho_{0}} \frac{d E}{d X}=\frac{0.153536}{\beta^{2}} \frac{Z}{A}\left\{F(\beta)-22 n I-2 \frac{C}{Z}-\delta\right\} .
$$

In this expression, $-\frac{1}{\rho_{0}} \frac{d E}{d X}$ is the mean energy loss per unit pathlength, in $\mathrm{MeV} /\left(\mathrm{g} \mathrm{cm}^{-2}\right)$. The term $2 \mathrm{C} / \mathrm{Z}$ is the shell correction, which is generally negligible at energies at which the density-effect correction $\delta$ is significant. For heavy charged particles (muons, pions, protons, ...)

${ }^{\star \star \star}$ Examination of our data indicates that the correlation is such that $\frac{a_{1}}{a_{2}}=n\left(m_{2}-m_{1}\right)$, where $n$ has a value in the range 4 to 8 . 


$$
F(\beta)=2 \ln \frac{2 m_{0} c^{2} \beta^{2}}{1-\beta^{2}}
$$

and for electrons

$F(\beta)=\ln \left|\frac{m_{0} c^{2} T \beta^{2}}{2\left(1-\beta^{2}\right)}\right|-\left(2 \sqrt{1-\beta^{2}}-1+\beta^{2}\right) \ln 2+1-\beta^{2}+\frac{1}{8}\left(1-\sqrt{1-\beta^{2}}\right)$.

As an example we consider the case of aluminum. We find $x_{0}=0.1708$, $x_{1}=3.0127, \delta\left(x_{0}\right)=0.12, \delta_{1}\left(x_{1}\right)=0.0015, a=0.08024, m=3.6345$, $\bar{c}=4.2395$. As a result, from Eqs. (9) and $(10), \delta(X)$ is given by:

$$
\begin{array}{lr}
\delta(x)=0.12\left[10^{2(x-0.1708)}\right] & (x<0.1708) \\
\delta(x)=4.6052 x+0.08024(3.0127-x)^{3.6345}-4.2395 \quad(0.1708<x<3.0127) \\
\delta(x)=4.6052 x-4.2395 & (x>3.0127) .
\end{array}
$$

We note that $x_{0}=0.1708$ corresponds to a momentum $p / m_{0} c=10^{0.1708}=1.482$, or a kinetic energy (in units $\mathrm{m}_{0} \mathrm{c}^{2}$ ) $\mathrm{T} / \mathrm{m}_{0} \mathrm{c}^{2}=0.788$.

\section{Acknowledaments}

The work carried out at Brookhaven National Laboratory (RMS) was supported by the U.S. Department of Energy under Contract No. DE-ACO2-76CH00016. The work carried out at the National Bureau of Standards (MJB and SMS) waS supported by the NBS Office of Standard Reference Data, by the Department of Energy (Office of Health and Environmental Research), and by the Office of Naval Research. 


\section{REFERENCES}

1. E. Fermi, Phys. Rev. 57, 485 (1940).

2. G. C. Wick, Nuovo Cimento 1, 302 (1943).

3. R. M. Sternheimer, Thesis, Univ. of Chicago (1946).

4. 0. Halpern and H. Hall, Phys. Rev. 73, 477 (1948).

5. R. M. Sternheimer, Phys. Rev. 88, 851 (1952).

6. R. M. Sternheimer, Phys Rev. 91, 256 (1953); 93, 351 (1954); 93, 1434 (1954).

7. R. M. Sternheimer, Phys. Rev. 103, 511 (1956).

8. R. M. Sternheimer, Phys. Rev. 145, 247 (1966).

9. R. M. Sternheimer, Phys. Rev. 164, 349 (1967).

10. R. M. Sternheimer and R. F. Peierls, Phys. Rev. B3, 3681 (1971).

11. R. M. Sternheimer, Phys. Rev. B24, 6288 (1981).

12. R. M. Sternheimer, S. M. Seltzer, and M. J. Berqer, Phys. Rev. B26, 6067 (1982); B27, 6971 (1983) (E).

13. S. M. Seltzer and M. J. Berger, Int. J. Appl. Radiat. Isot. 33, 1189 (1982).

14. M. J. Berger and S. M. Seltzer, "Stopping Powers and Ranaes of Electrons and Positrons" (2nd Ed.), National Bureau of Standards Report No. NBSIR 82-2550A (1983).

15. T. A. Carlson, Photoelectron and Auger Spectroscopy (Plenum Press, New York, 1975), Appendix 1.

16. U. Fano, Ann. Rev. Nucl. Sci. 13, 1 (1963).

17. H. Raether, Excitation of Plasmons and Interband Transitions by Electrons (Springer-VerTag, Berlin, Heidelberg, New Tork, 1980).

18. D. J. Isaacson. "Positron Trappings of Defects in Solids," Pho. Disertation, New York University (1981).

19. A. Mann and W. Brandt, Phys. Rev. B 24, 4999 (1981).

20. J. F. Ziegler, J. P. Biersack, and U. Littmark, Proc. of U.S.-Japan Seminar on Charged Particle Penetration Phenomena, Oak Ridge National Laboratory Report CONF-820131 (1982), p. 88. 
21. R. M. Sternheimer, Phys. Rev. A15, 1817 (1977).

22. R. M. Sternheimer, Trans. New York Acad. Sci., Series II, 40, 190 (1980).

23. H. A. Bethe, Ann. Phys. (Leipzig) 5,325 (1930).

24. F. Bloch, Z. Phys. 81, 363 (1933).

25. ICRU Report 10b, "Physical aspects of irradiation. Recommendations of the International Commission on Radiological Units and Measurements," published as National Bureau of Standards Handbook 85 (1964).

26. "Report of the task group on reference man," International Commission on Radiological Protection, Pergamon Press, New York (19/5). 


\section{Definition of Parameters in Tables I and II}

$Z \quad$ Atomic number

Z/A Ratio of atomic number to atomic weight

I Mean excitation energy (in eV)

po Density (in $\mathrm{g} / \mathrm{cm}^{3}$ )

$h \nu_{p} \quad$ Plasma energy (in units $\in V$ ) [Eq. (4)]

- Sternheimer adjustment factor for the atomic excitation energies

[Eqs. (3) and (8)].

$-C \quad[E q .(11)]$.

$\left.\begin{array}{l}x_{0} \\ x_{1}\end{array}\right\} \quad$ Parameters in fitting formulas [Eqs. (9) and (10)].

a

So Density-effect value used as fitting parameter in Eq. (25).

$\Delta_{\max } \quad$ Upper bound for the error inherent in fitting procedure. The absolute value of the difference between the fitted and the numerical value of $\delta$ is at all energies smaller than $\Delta_{\max }$.

The composition of the compounds and mixtures in Table II, in terms of fractions by weight of the atomic constituents, can be found in Seltzer and Berger. ${ }^{13}$ The designation (ICRU) indicates tissue compositions adopted by the International Commission on Radiation Units and Measurements, ${ }^{25}$ and the designation (ICRP) indicates tissue compositions adopted by the International Commission on Radiological Protection. ${ }^{26}$ 

000NN 0000000

manmann

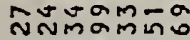

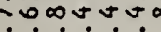

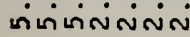

NMMONTN

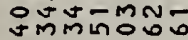
0000000

mInNกNก! กลกำกับ

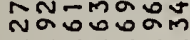
$\dot{m}=\dot{m}=-\infty$

MaNGNIn mun-ำำ D.N-0.0 $\therefore$ No00:

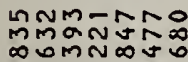

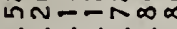
वiñminiN

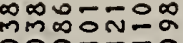
$000 \div \div 0$ 0000000

이잉 0000000

DNMMN-N ำกำํำ OूลNลNล miniminimin

ONamor

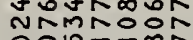

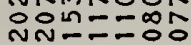
0000000

ormmo-n

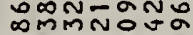
sinmNớ Nंvivivim

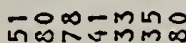

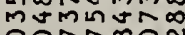
oONRDoN io---io 스ํㅇํำำำ 은ํํ영ํํ ninoo:-in

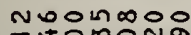

a Jயำกำก ‥-NiN

DOJ十0N

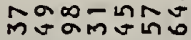
NN-NiNiNi

$M-m=\infty O N$ NONDOoromios Nim

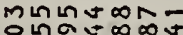
कin i000000

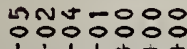

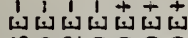

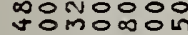
mo0moñ क0-10-Nin

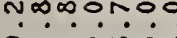
ลกษ์

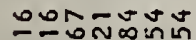
กักํำกี่ aूa 0000000

$N$

- -Nmono<smiles>[SiH2]</smiles>

เกิ

\section{0mmmto-}

由

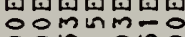
orominnt

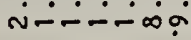

0000000

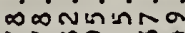
NR⿻上丨=m

\section{บับNำ}

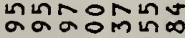

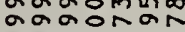
vavinuta 0000000

bondar = $=$

舟正士00 0000000

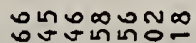

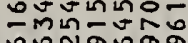
minmininis

MUTONAJ

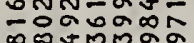
OO-NM0000000

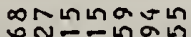

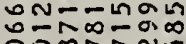
minininivo

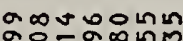
寸ró -Nen$00000-1$

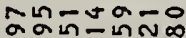

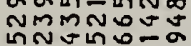

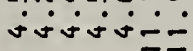

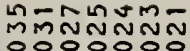
00000000 0000000

บํบㄴ 0000000 ตีเป็น์ั

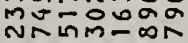
Nóㅇoㅇa Niminimiño

AMNNom

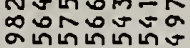
0000000

Nลัก็ำก I=00000 minisinimion

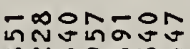

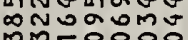
0000000

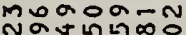
जूas ח0.0.N

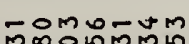
mo음ำ inivin-:

웅은 moñㅇำ $\because \because$-niñ

Dolnmana 윤요 0n-ain-0 $00000 \mathrm{~mm}$ 0000000

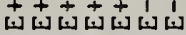
잉요

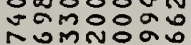
- ininin-

오움데 món.

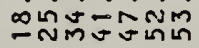

음ㅇㅇㅇํำ



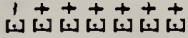
0000000 운원응ㅇ ํำ क-ñonin

0000000 óminos உேํำำ

0000000 - - umiñN ดัลกับลกล

Nōnmmmm

న⿻心㇒𠃋

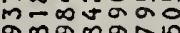

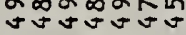

$0000000^{\circ}$

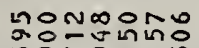

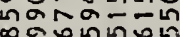

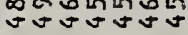
0000000 NMELRND ดำกักลก

on
ำํำำำำ 0000000

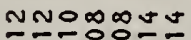
-000000

Mํํㄴㅁำ

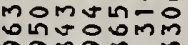
Ninivimin

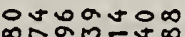

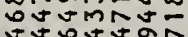
?-1.0ㅇ. 0000000

ํํํํํํํㅇ

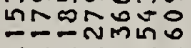
miniminimín

NNDJano రㄴํํํํำ OOOLOONm ioio000

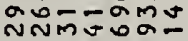

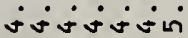

ToONNT-

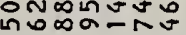
กNiñniñ

$N \infty$ InONำกำ

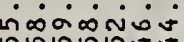

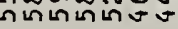

양유

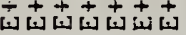
웅유암우이 승여음유

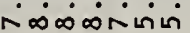

0000000 ON-nojo

ํำ

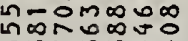

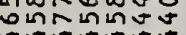
0000000

MNNNNNN 0000000 0000000

乎00ปㄴ 0000000

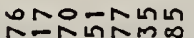
ㅍํ는ำ miniminimió

$m \infty \operatorname{mo-\operatorname {ln}}$ บ In⿴囗十)-

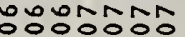
0000000

NUa⿻ №vañ

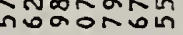
minuivimió

กำ Nํำกำ -NInNLUm 00--000

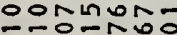

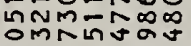
ที่-Nónin

งañon 으유om

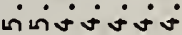

avinomna

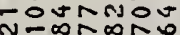
in- 둥

कun iñNNDO

andange

$n=0=0 N$

no--mio

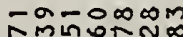
ดักลำ

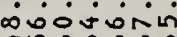

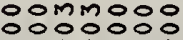

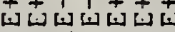
OONNmOONO

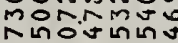

जिंति-ño

웅두웅

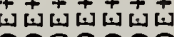
SONO-Oำ

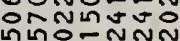
$\infty \infty-\cdots-1$

0000000 Nominiso

0000000 minion

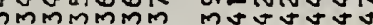

+omáán Thmning

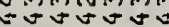
0000000

ㅇำกำกำ

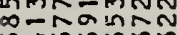

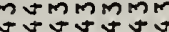
0000000

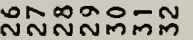

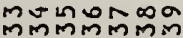

ก लं-

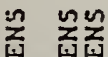




\begin{tabular}{|c|c|c|c|c|c|c|c|}
\hline & 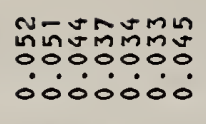 & 00 & $\begin{array}{l}\sigma 000000 \\
0000000\end{array}$ & 0000 & $\begin{array}{l}\text { NNNNNNNO } \\
000000 \\
000000\end{array}$ & 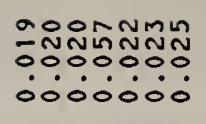 & $\because 0$ \\
\hline & $\therefore 0$ & 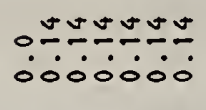 & 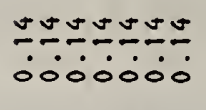 & $\begin{array}{l} \pm \pm \\
000\end{array}$ & 000000 & $\therefore c$ & $\because 0$ \\
\hline & 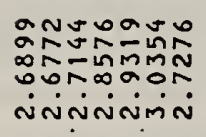 & ํㅜㅇ & 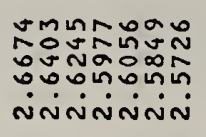 & กิ๊ำ & 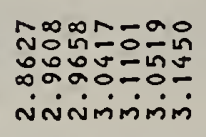 & min & 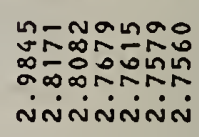 \\
\hline & 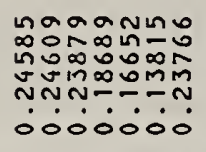 & 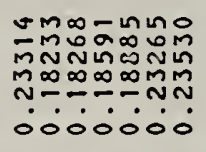 & 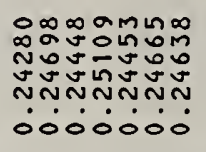 & 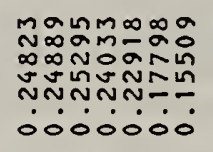 & $\begin{array}{l}n \tilde{N} \\
\therefore \therefore\end{array}$ & $\begin{array}{l}\text { } \\
25 \\
00 \\
00\end{array}$ & 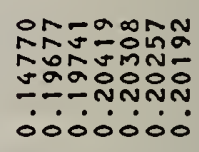 \\
\hline & 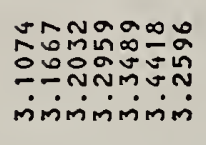 & 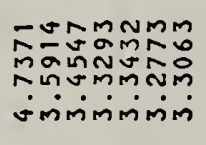 & 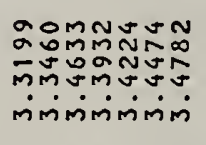 & 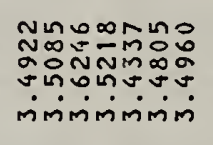 & vin & ${ }^{\infty} \cdot$ & inin \\
\hline & 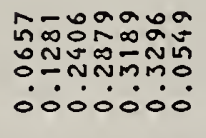 & 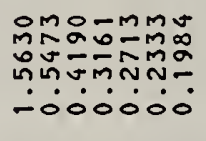 & 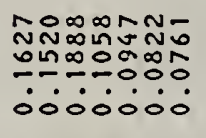 & 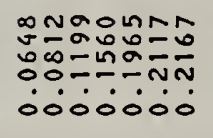 & 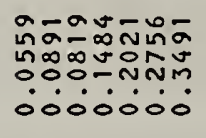 & m. & 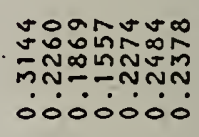 \\
\hline & 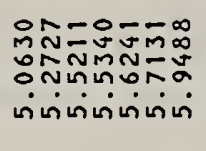 & 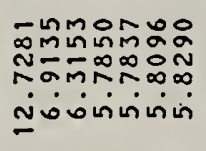 & 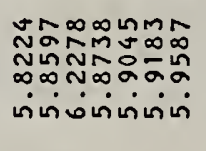 & 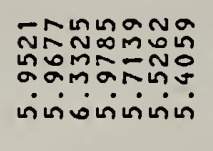 & min & 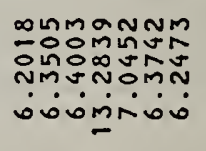 & $\dot{b}$ \\
\hline & 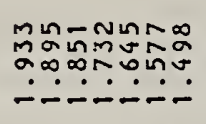 & & & $\%$ & & & \\
\hline & & & & & & & \\
\hline & 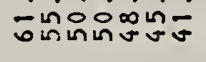 & $n$ & 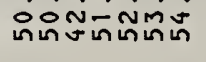 & 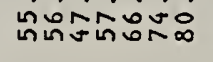 & : & & 소 \\
\hline $\overrightarrow{0}$ & 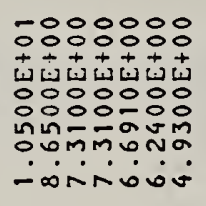 & 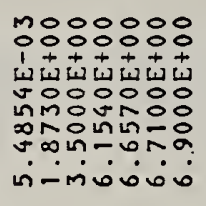 & 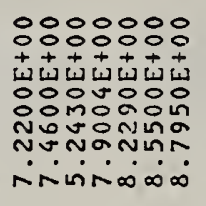 & 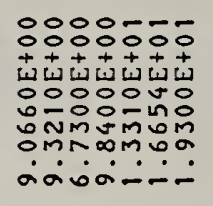 & 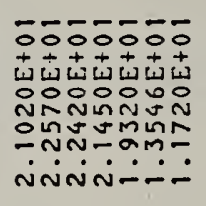 & 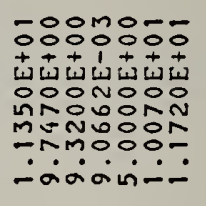 & 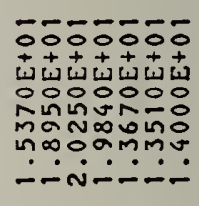 \\
\hline $\bar{z}$ & 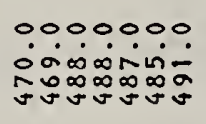 & 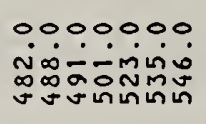 & $\begin{array}{l}000 \\
000 \\
\text { iñ }\end{array}$ & 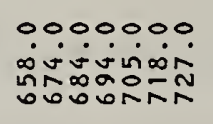 & . & :0. & 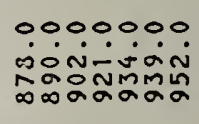 \\
\hline & 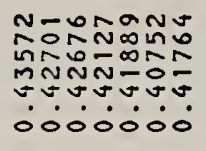 & 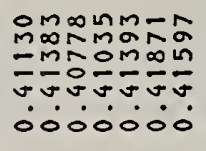 & 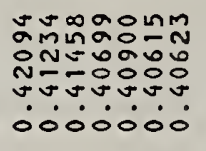 & 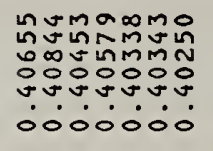 & 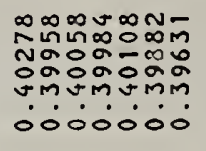 & 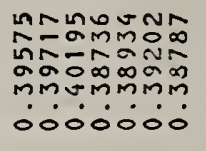 & 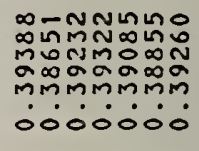 \\
\hline & 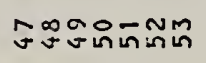 & 10 - & 5 & $-N$ & $\bar{x}$ & & \\
\hline
\end{tabular}




\begin{tabular}{|c|c|c|c|c|c|c|c|c|c|}
\hline 佩 & 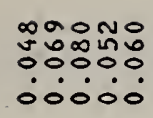 & 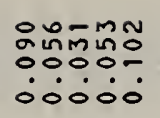 & 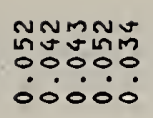 & $\begin{array}{l}\text { 윺ำ } \\
\text { Mñ } \\
0000 \\
00000\end{array}$ & 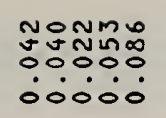 & 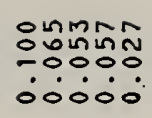 & $\begin{array}{l}\text { MUUN } \\
00 \bar{N} \\
000 \\
00000\end{array}$ & $\begin{array}{l}\bar{\sigma}-000 m \\
00000 \\
0000 \\
00000\end{array}$ & 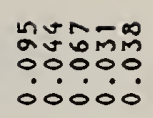 \\
\hline$=$ & 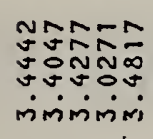 & 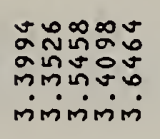 & 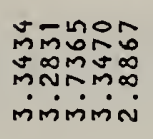 & 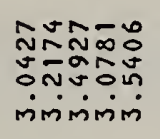 & 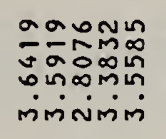 & 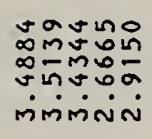 & 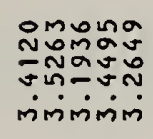 & 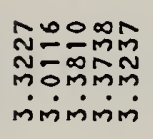 & mis \\
\hline סז & $\begin{array}{l}\text { mon } \\
\text { o은 } \\
0=\frac{1}{0} \\
000\end{array}$ & 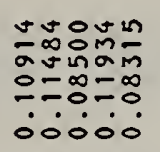 & 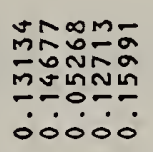 & 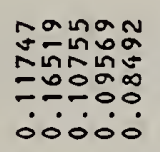 & 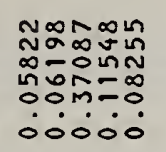 & 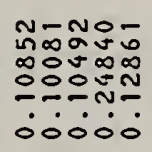 & 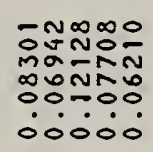 & 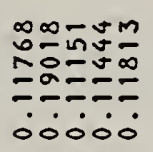 & $\begin{array}{l}0 \\
\vdots \\
0 \\
0 \\
0 \\
\vdots \\
0\end{array}$ \\
\hline & 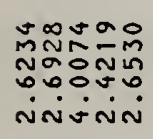 & 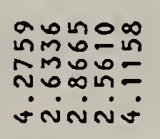 & 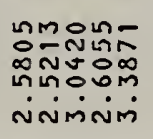 & 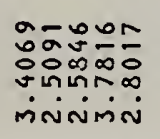 & 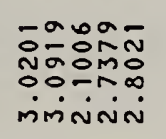 & 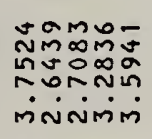 & 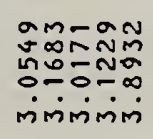 & 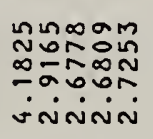 & \\
\hline & \begin{tabular}{l} 
Na \\
mã \\
\hdashline 0 \\
$\therefore 0$
\end{tabular} & 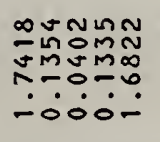 & 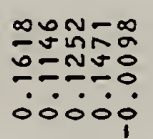 & 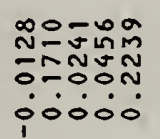 & 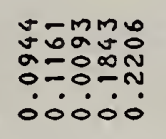 & 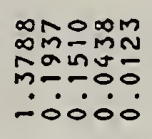 & 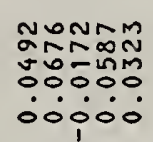 & $\frac{\infty}{0}$ & \\
\hline ن & 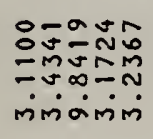 & 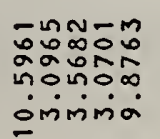 & 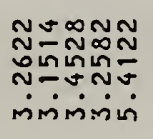 & 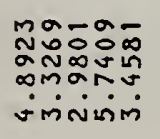 & 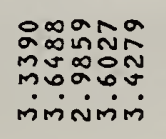 & 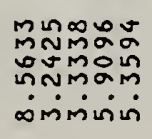 & 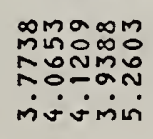 & 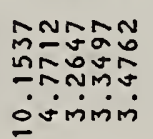 & \\
\hline a & & 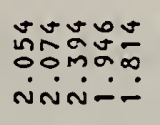 & מ็นmำ & 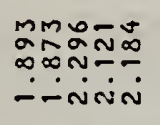 & 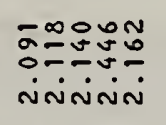 & 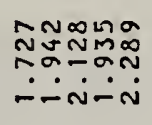 & $\begin{array}{l}\text { ENMRN } \\
\text { ENANN } \\
\text { NN-NN }\end{array}$ & 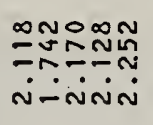 & \\
\hline & 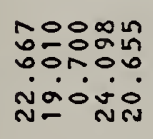 & 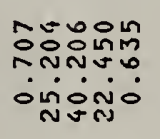 & & 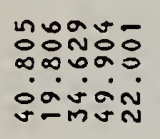 & 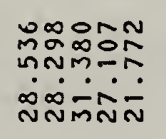 & 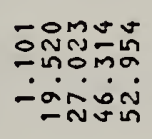 & 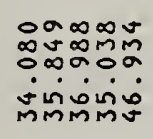 & 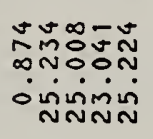 & 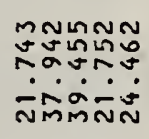 \\
\hline 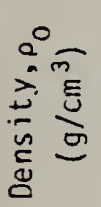 & 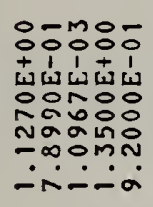 & 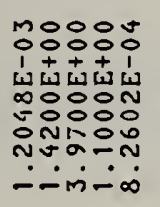 & 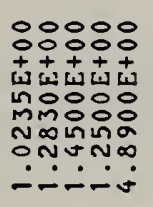 & 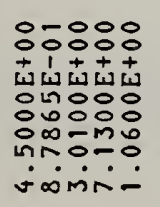 & 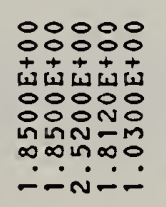 & 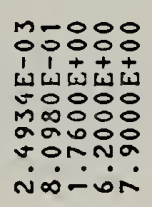 & 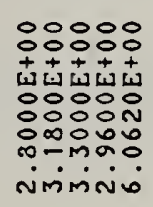 & 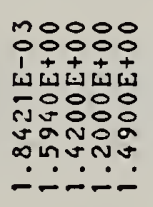 & 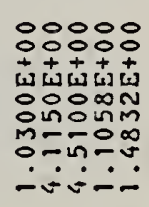 \\
\hline- d & -NNv & 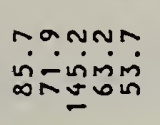 & $\begin{array}{l}\text { vinava } \\
\text { boinivin } \\
\text { obing }\end{array}$ & ษัN-N & 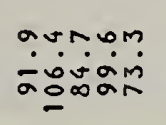 & 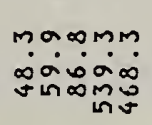 & 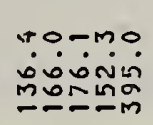 & $\because$ : & $\ddot{0}$ \\
\hline- & 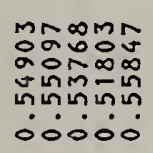 & 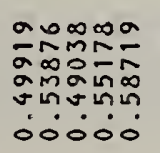 & 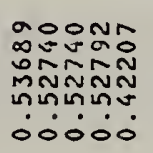 & 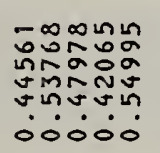 & 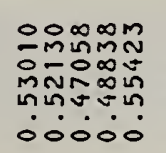 & 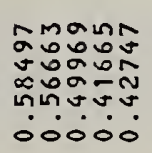 & 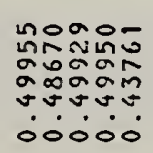 & 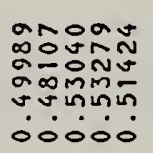 & 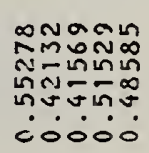 \\
\hline
\end{tabular}

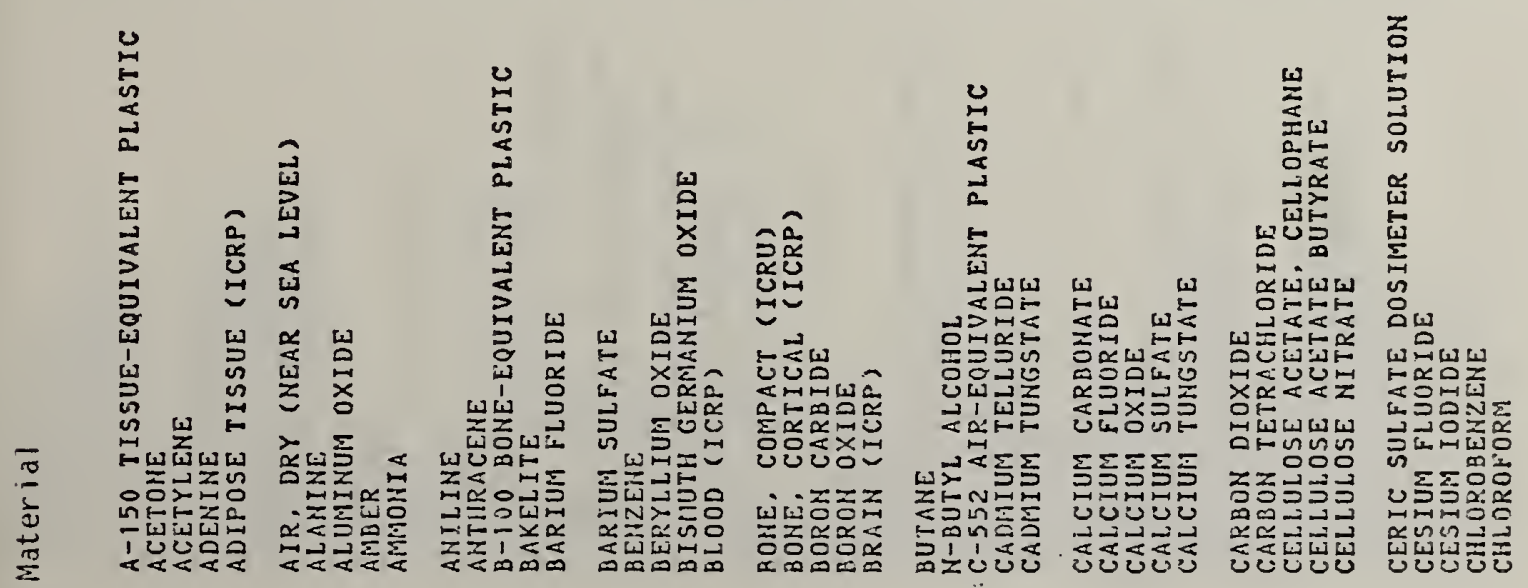




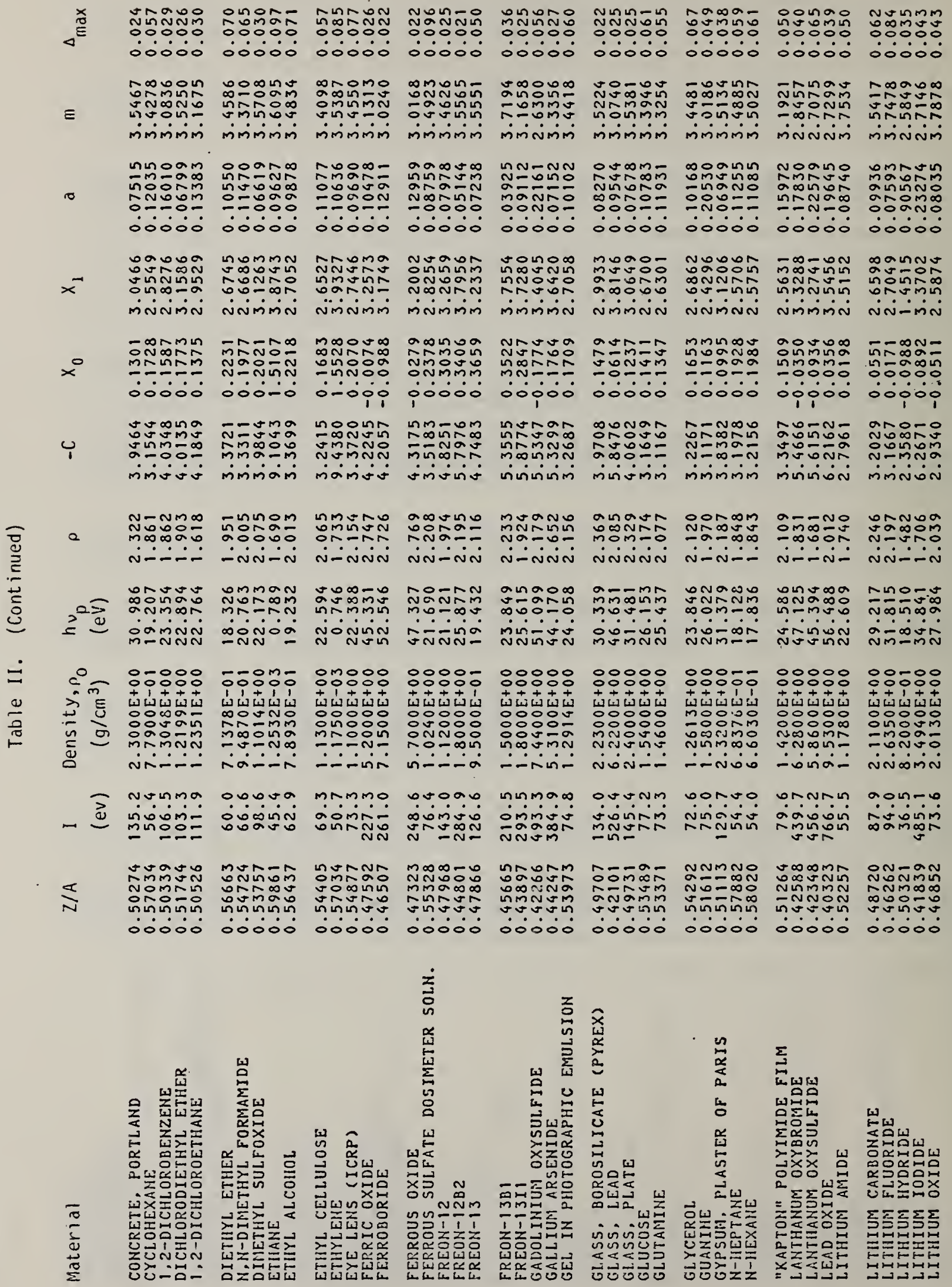




\begin{tabular}{|c|c|c|c|c|c|c|c|c|c|}
\hline$\overbrace{\triangleleft}^{\stackrel{x}{E}}$ & 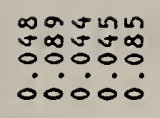 & 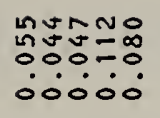 & 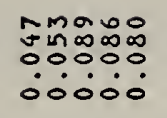 & 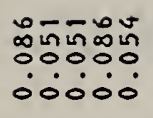 & $\begin{array}{l}\text { ํํํํํำก } \\
00000 \\
00000\end{array}$ & 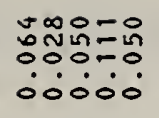 & 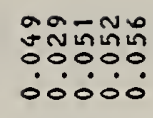 & 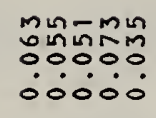 & $\begin{array}{l}n \text { nnn: } \\
000 \\
000\end{array}$ \\
\hline$E$ & 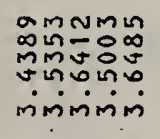 & 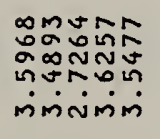 & 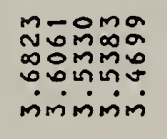 & 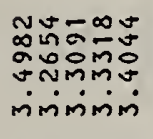 & 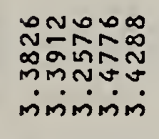 & 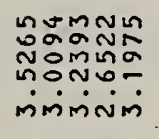 & 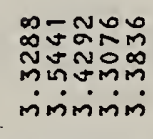 & 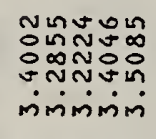 & inm \\
\hline 0 & 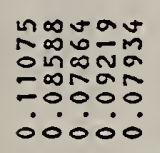 & 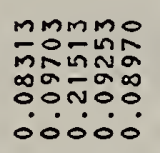 & 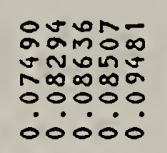 & 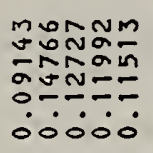 & 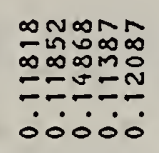 & 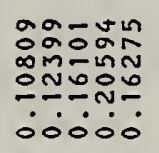 & 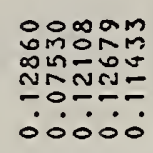 & 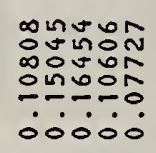 & \\
\hline$x^{\overrightarrow{ }}$ & 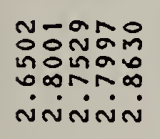 & 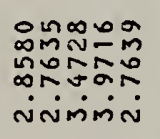 & 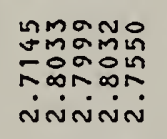 & 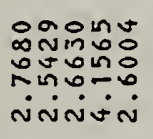 & 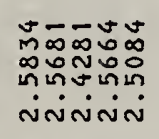 & 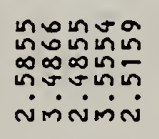 & 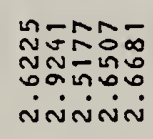 & 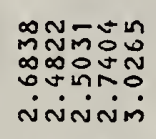 & \\
\hline & 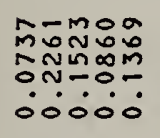 & 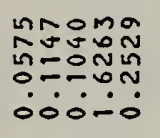 & 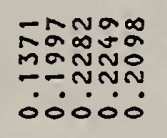 & 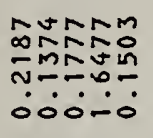 & $\begin{array}{l}\text { va } \\
\vdots \infty \\
0 \\
0 \\
0\end{array}$ & $\begin{array}{l}\text { D० } \\
\text { o: } \\
\text { Nं: } \\
00\end{array}$ & $\because$ & 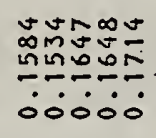 & \\
\hline ب & 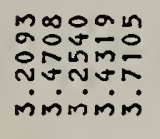 & 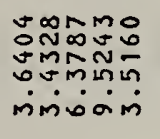 & 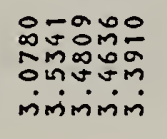 & 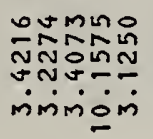 & 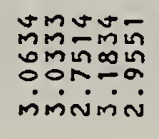 & 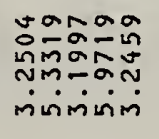 & 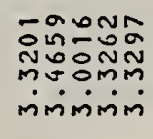 & 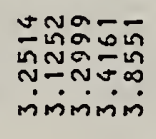 & \\
\hline a & 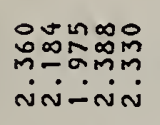 & 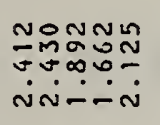 & 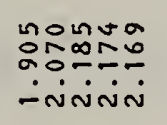 & 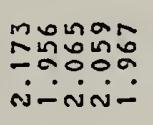 & 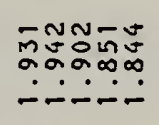 & 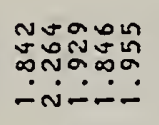 & $\begin{array}{l}\text { :̊ } \\
\text { :ू } \\
\dot{n}-\end{array}$ & 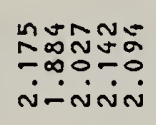 & $\begin{array}{l}0 \\
0= \\
\text { in }\end{array}$ \\
\hline (ब) & 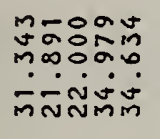 & 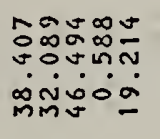 & 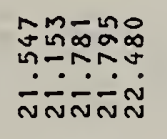 & 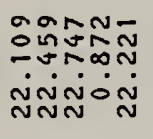 & 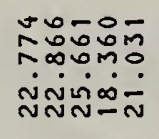 & 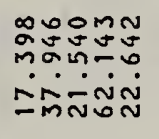 & 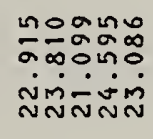 & 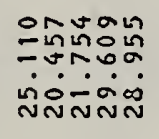 & 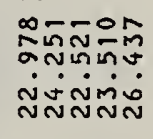 \\
\hline 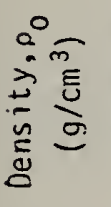 & 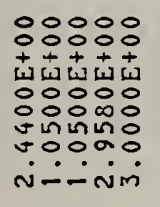 & 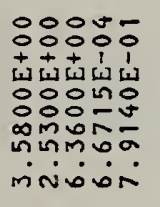 & 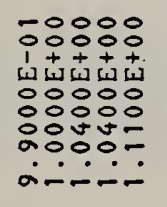 & 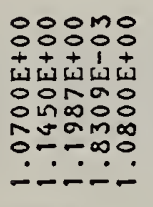 & 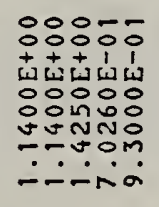 & 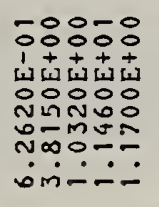 & 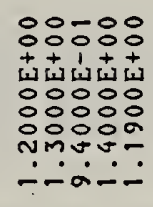 & 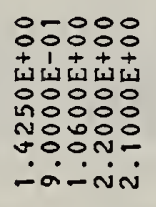 & 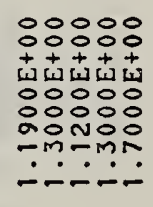 \\
\hline$-\overline{3}$ & 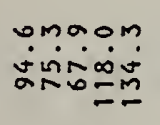 & 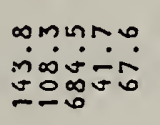 & & 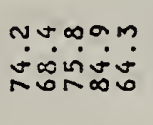 & & & & 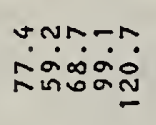 & $i$ \\
\hline 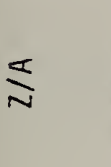 & 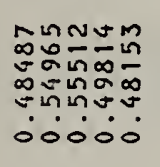 & 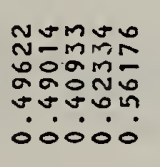 & 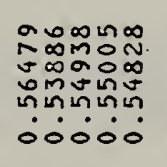 & 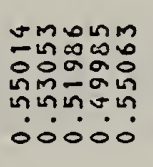 & 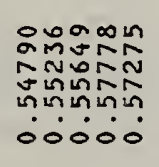 & 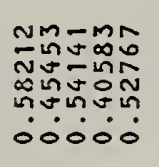 & 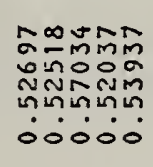 & 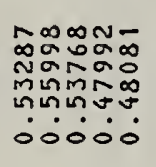 & 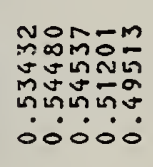 \\
\hline$\frac{5}{5}$ & 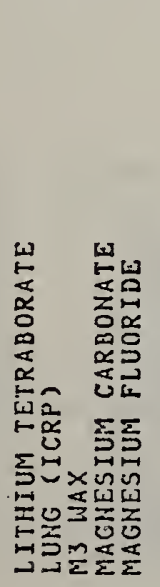 & 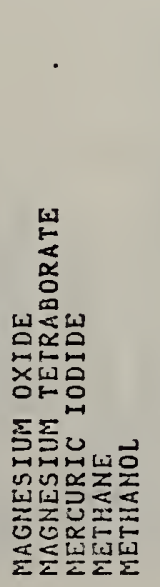 & 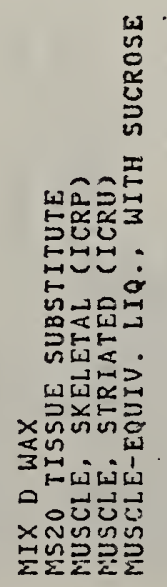 & 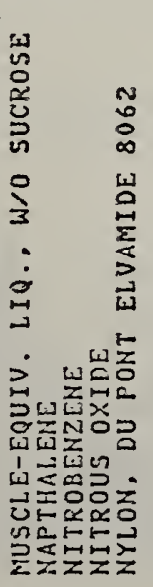 & 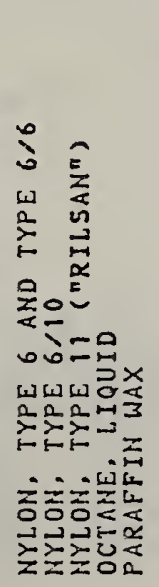 & 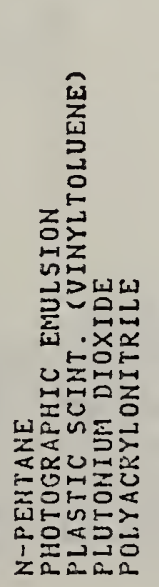 & 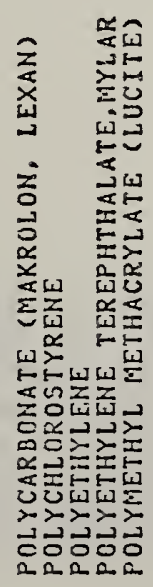 & 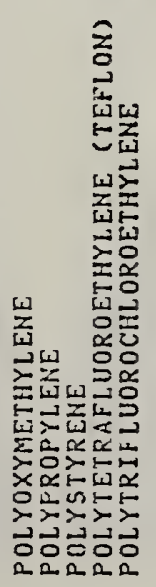 & 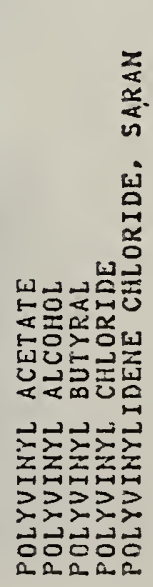 \\
\hline
\end{tabular}




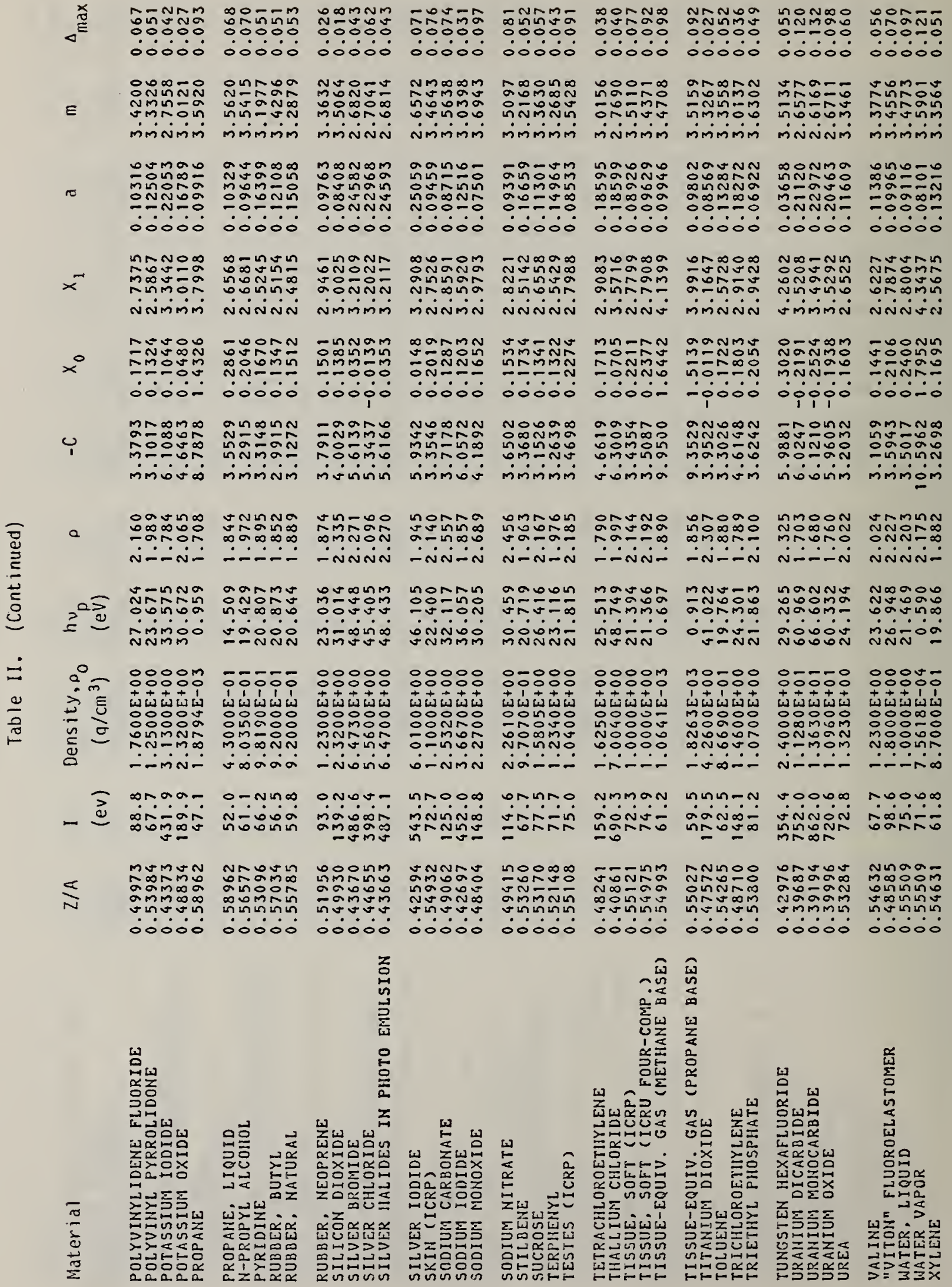




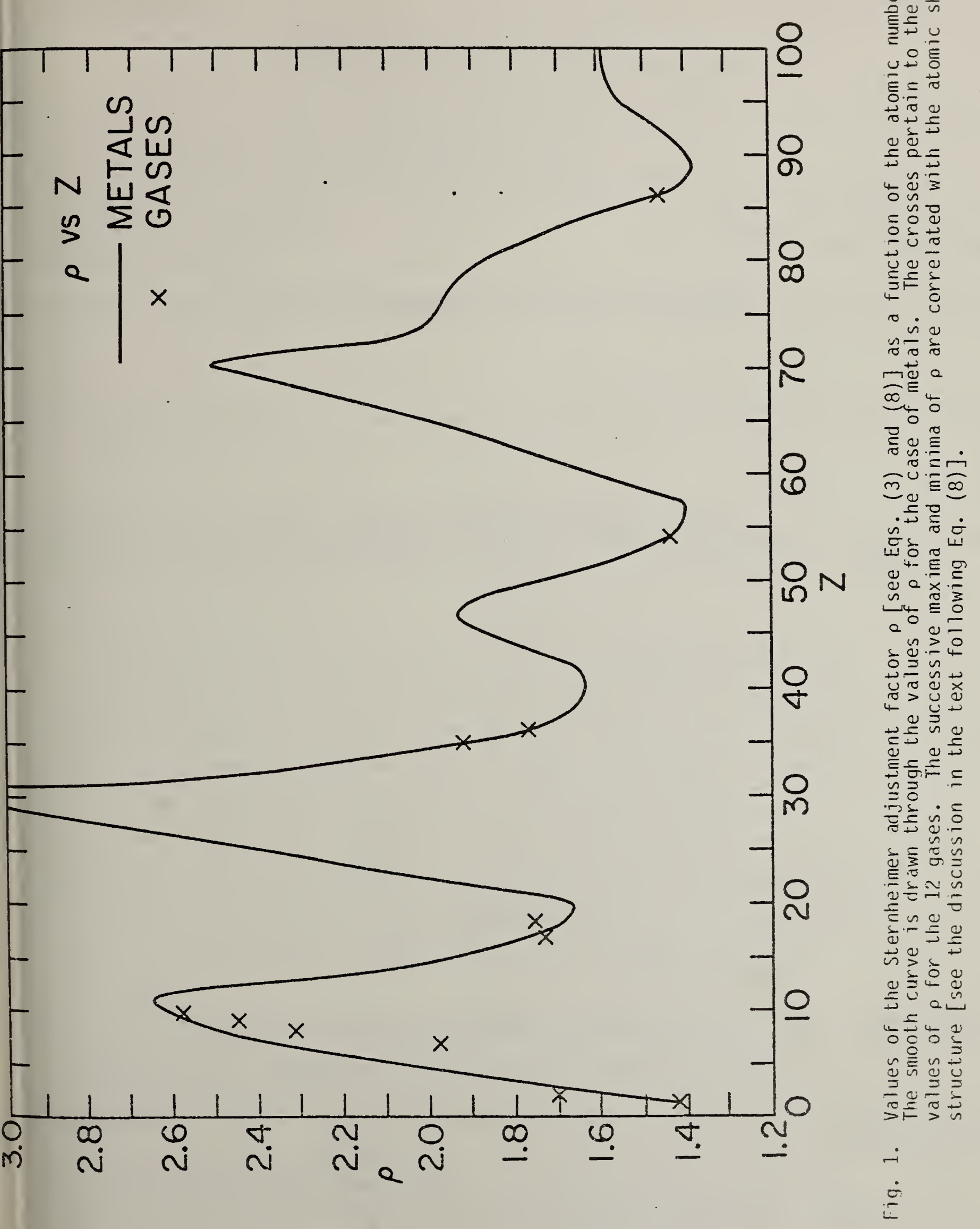



BIBLIOGRAPHIC DATA

SHEET (See instructions)

\begin{tabular}{|c|c|}
\hline $\begin{array}{l}\text { 1. PUBLICATION OR } \\
\text { REPORT NO. }\end{array}$ & 2. Performing Organ. Report No o 3. Publication Date \\
\hline
\end{tabular}

4. TITLE AND SUBTITLE

DENSITY EFFECT FOR THE IONIZATION LOSS

OF CHARGED PARTICLES IN VARIOUS SUBSTANCES

5. AUTHOR(S)

R. M. Sternheimer, M. J. Berger and S. M. Seltzer

6. PERFORMING ORGANIZATION (If joint or other than N8S, see instructions)

7. Contracd Grant No.

NATIONAL BUREAU OF STANDARDS

DEPARTMENT OF COMMERCE

WASHINGTON, D.C. 20234

9. SPONSORING ORGANIZATION NAME AND COMPLETE ADDRESS (Street, City. State, ZIP)

8. Type of Report \& Period Covered

10. SUPPLEMENTARY NOTES

Document describes a computer program; SF-185, FIPS Software Summary, is attached.

11. ABSTRACT (A 200-word or less factual summary of most significant information. If document includes $c$ significant bibliography or literature survey. mention it here)

The density-effect correction $\delta(\beta)$ for the ionization energy loss of charged particles has beeil evaluated for a total of 278 substances including 98 cases of elements of the Periodic Table (12 gases and 86 condensed materials, including liquid hydrogen and graphite of three different densities) and including also 180 chemical compounds and substances of biological interest (13 gases and 167 liquid or solid substances). In the calculations, up-to-date values of the mean excitation potential I and of the atomic absorption edges $h \nu_{i}$ were employed as input data for the general equations for $\delta(\beta)$ previously derived by Sternheimer.

12. KEY WORDS (Six io twelve entries; alphabetical order; capitalize only proper names; and separate key words by semicolons)

charged particles; compounds; density effect; elements; mean excitation energies; stopping power.

13. AVAILABILITY

Unlimited

$\square$ For Official Distribution. Do Not Release to NTIS

$\square$ Order From Superintendent of Documents, U.S. Government Printing Office, Washingtor, D.C. 20402.

14. NO. OF

PRINTED PAGES

Order From National Technical Information Service (NTIS), Springfield, VA. 22161 
